Prepared in cooperation with the U.S. Fish and Wildlife Service

\title{
Jaguar Taxonomy and Genetic Diversity for Southern Arizona, United States, and Sonora, Mexico
}

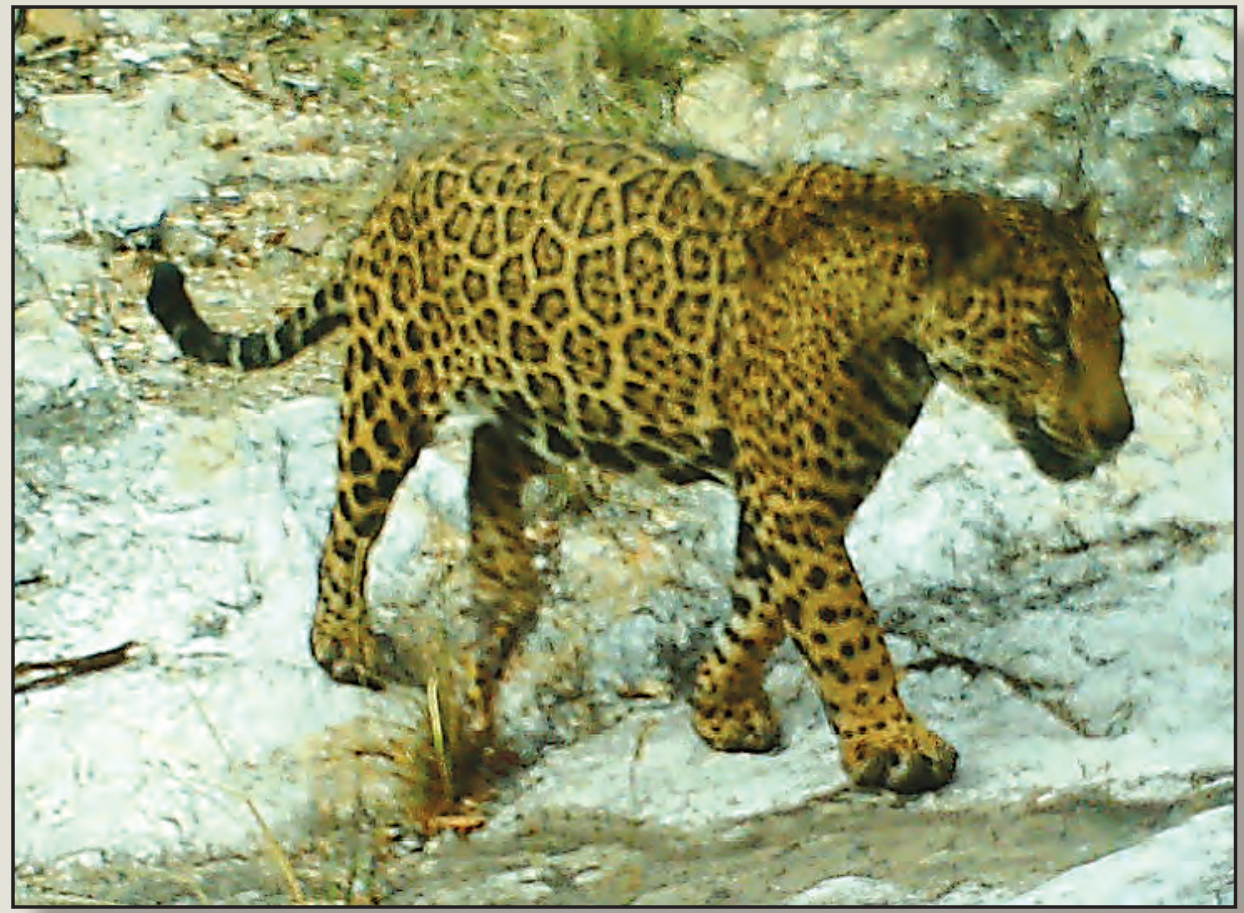

Open-File Report 2016-1109 
Cover: Photograph of male jaguar (Panthera onca), April 10, 2014. Photograph courtesy of University of Arizona and U.S. Fish and Wildlife Service. 


\section{Jaguar Taxonomy and Genetic Diversity for Southern Arizona, United States, and Sonora, Mexico}

By Melanie Culver and Alexander Ochoa Hein

Prepared in cooperation with the U.S. Fish and Wildlife Service

Open-File Report 2016-1109

U.S. Department of the Interior

U.S. Geological Survey 


\section{U.S. Department of the Interior \\ SALLY JEWELL, Secretary}

\section{U.S. Geological Survey \\ Suzette M. Kimball, Director}

U.S. Geological Survey, Reston, Virginia: 2016

For more information on the USGS—-the Federal source for science about the Earth,

its natural and living resources, natural hazards, and the environment-visit

http://www.usgs.gov/ or call 1-888-ASK-USGS (1-888-275-8747).

For an overview of USGS information products, including maps, imagery, and publications, visit http://store.usgs.gov.

Findings and conclusions in this article are those of the authors and do not necessarily represent the views of the U.S. Fish and Wildlife Service.

Any use of trade, firm, or product names is for descriptive purposes only and does not imply endorsement by the U.S. Government.

Although this information product, for the most part, is in the public domain, it also may contain copyrighted materials as noted in the text. Permission to reproduce copyrighted items must be secured from the copyright owner.

\section{Suggested citation:}

Culver, Melanie and Hein, A.O., 2016, Jaguar taxonomy and genetic diversity for southern Arizona, United States, and Sonora, Mexico: U.S. Geological Survey Open-File Report 2016-1109, 20 p., http://dx.doi.org/10.3133/ofr20161109. 


\section{Contents}

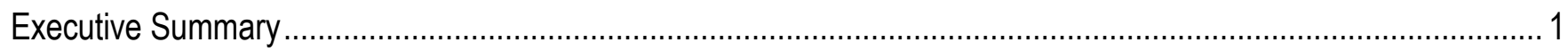

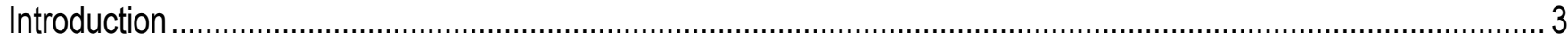

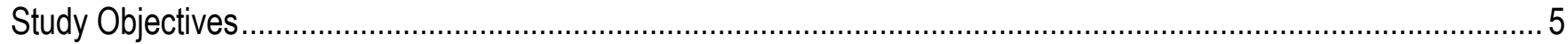

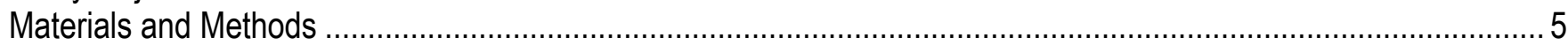

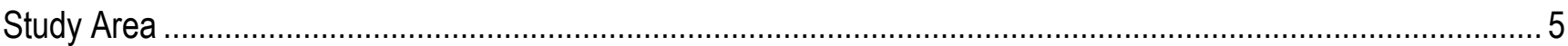

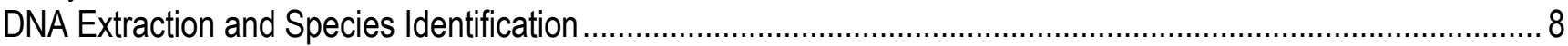

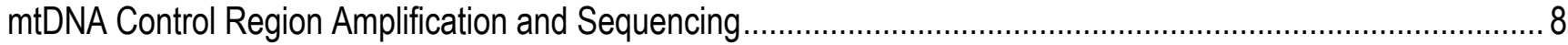

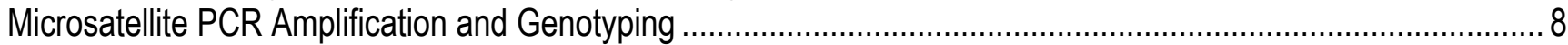

Final Sample Inclusions for Analyses.........................................................................................

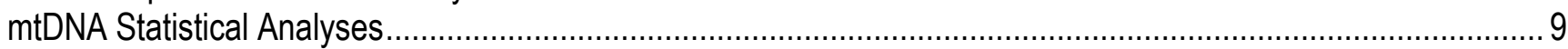

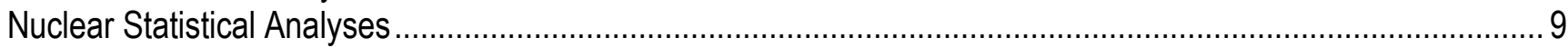

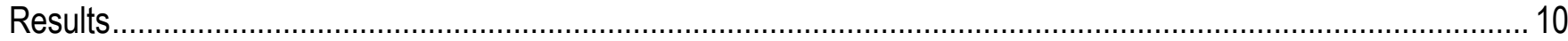

mtDNA Control Region Genetic Diversity and Structure ......................................................................... 10

Nuclear Genetic Diversity and Structure ............................................................................................ 12

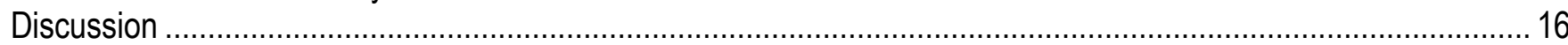

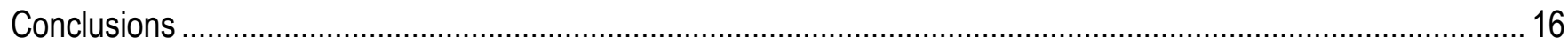

Management Implications for Jaguars in Arizona/New Mexico and Mexico …............................................. 17

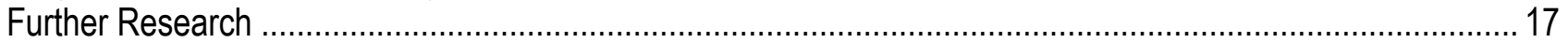

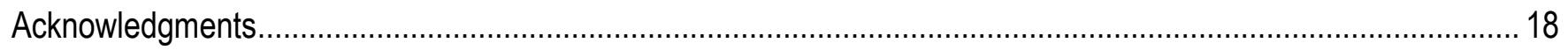

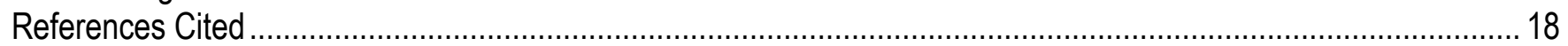

\section{Figures}

Figure 1. Maps showing historical and current geographical distribution of jaguars [modified from Oliveira (1994) and Eizirik and others (2001)], in North, Central, and South America, and the location of Northern and Southern populations with respect to the Amazon River (right panel); and Northwestern Jaguar Recovery Unit (NJRU) population [modified from Sanderson and Fisher (2013) in North America (left panel) ................................ 4 Figure 2. Minimum-spanning network diagram showing phylogenetic and geographical relations among jaguar mitochondrial DNA control region haplotypes (circles) (modified from Eizirik and others, 2001) ............................ 11 Figure 3. Graph showing number of genetic clusters $(K)$ as function of model value of Delta $K$, as

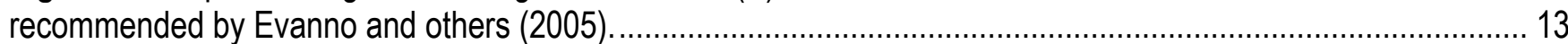

Figure 4. Graph showing population assignment test of jaguars according to their geographic origin (Northwestern Jaguar Recovery Unit [NJRU], Northern, Southern).................................................................. 13

\section{Tables}

Table 1. Jaguar samples analyzed in this study

Table 2. Mitochondrial genetic diversity estimates for each jaguar population in this study and the overall sample set. 10

Table 3. Pairwise genetic differentiation $\left(F_{S T}\right)$ values between jaguar populations in this study..... 12 Table 4. Nuclear genetic diversity $\left(H_{E}\right.$ and $\left.A\right)$ and inbreeding $\left(F_{I S}\right)$ values for each jaguar population and the overall sample set. 


\section{Conversion Factors}

International System of Units to Inch/Pound

\begin{tabular}{lcl}
\hline Multiply & By & To obtain \\
\hline & Area & \\
\hline square kilometer $\left(\mathrm{km}^{2}\right)$ & 247.1 & acre \\
\hline
\end{tabular}

\section{Datum}

Horizontal coordinate information is referenced to the North American Datum of 1983 (NAD 83). 


\title{
Jaguar Taxonomy and Genetic Diversity for Southern Arizona, United States, and Sonora, Mexico
}

\author{
By Melanie Culver ${ }^{1}, 2,3$ and Alexander Ochoa Hein ${ }^{3}$
}

\section{Executive Summary}

The jaguar is the largest Neotropical felid and the only extant representative of the genus Panthera in the Americas. In recorded history, the jaguars range has extended from the Southern United States, throughout Mexico, to Central and South America, and they occupy a wide variety of habitats. A previous jaguar genetic study found high historical levels of gene flow among jaguar populations over broad areas but did not include any samples of jaguar from the States of Arizona, United States, or Sonora, Mexico. Arizona and Sonora have been part of the historical distribution of jaguars; however, poaching and habitat fragmentation have limited their distribution until they were declared extinct in the United States and endangered in Sonora. Therefore, a need was apparent to have this northernmost (Arizona/Sonora) jaguar population included in an overall jaguar molecular taxonomy and genetic diversity analyses. In this study, we used molecular genetic markers to examine diversity and taxonomy for jaguars in the Northwestern Jaguar Recovery Unit (NJRU; Sonora, Sinaloa, and Jalisco, Mexico; and southern Arizona and New Mexico, United States) relative to jaguars in other parts of the jaguar range (Central and South America). The objectives of this study were to:

1. Collect opportunistic jaguar samples (hide, blood, hair, saliva, and scat), from historical and current individuals, that originated in NJRU areas of Arizona, New Mexico, and Sonora;

2. Use these samples to assess molecular taxonomy of NJRU jaguars compared to data from a previous study of jaguars rangewide; and

3. Develop suggestions for conservation of NJRU jaguars based on the results.

Analyses were performed on three populations of jaguars: (1) NJRU; (2) Northern (north of the Amazon River to the State of San Luis Potosi on the Gulf coast of Mexico); and (3) Southern (south of the Amazon River to the Chaco region of Paraguay). We isolated DNA from 27 jaguar samples, 26 of which were from the NJRU. The maternally inherited mitochondrial DNA (mtDNA) molecule, which contains 37 genes and a non-coding region known as the control region, was used because of its characteristic high levels of genetic variation (it contains many base pair changes; base pairs make up the sequence of DNA). The control region is the segment of the mtDNA molecule that we amplified using polymerase chain reaction (PCR). Microsatellites, repeated sequences of 2-6 nucleotides (or base pairs) long, also were used for this study because of their high levels of genetic variation (presence of many different sized alleles). We amplified 28 nuclear microsatellite DNA loci using PCR, from which we ended up using 22 loci for quality control reasons. We also obtained 3 DNA samples from Ivonne

\footnotetext{
${ }^{1}$ U.S. Geological Survey.

${ }^{2}$ Arizona Cooperative Fish and Wildlife Research Unit.

${ }^{3}$ University of Arizona, School of Natural Resources and the Environment.
} 
Cassaigne at the National Autonomous University of Mexico (UNAM), 37 mtDNA control region sequences from the GenBank database, and microsatellite genotypes for 42 individuals from Eduardo Eizirik at Pontifícia Universidade Católica do Rio Grande do Sul (PUCRS), for comparison with the data we generated for this study. The total mtDNA control region dataset included 54 sequences, and we analyzed 715 base pairs. We found 7 haplotypes in NJRU jaguars, 11 haplotypes in Northern jaguars, and 11 haplotypes in Southern jaguars, almost all unique to their particular geographic region. In the populations examined (NJRU, Northern, and Southern), mean allelic richness values ranged from 3.667 to 4.871 , mean observed heterozygosities ranged from 0.434 to 0.653 , and mean expected heterozygosities ranged from 0.614 to 0.764 . The NJRU population has lower levels of nuclear genetic diversity than Northern and Southern populations. We found five unique mtDNA control region haplotypes in jaguars from Arizona and Sonora examined in this study, not found anywhere else in the jaguar's range; the other two haplotypes found in the NJRU population come from Jalisco and Sinaloa, Mexico, and are not unique but are shared with the Northern population. NJRU jaguars show lower levels of mitochondrial and nuclear genetic diversity when compared with other jaguar populations (Northern and Southern), supporting a recent colonization (in evolutionary time) of jaguars into Arizona, New Mexico, and Sonora. Because of the exclusive geographic location of mtDNA haplotypes in the haplotype network, it appears that there have been no female jaguar dispersal events beyond the Arizona/Sonora area in recent evolutionary times. Male dispersal movements are greater than female dispersal movements, given the lower genetic differentiation observed with microsatellite (nuclear) markers among the NJRU, Northern, and Southern populations.

Conservation and management strategies for jaguars living exclusively in Arizona, New Mexico, United States, and Sonora, Mexico, require connectivity to, and protection of, source and breeding populations from other areas of Mexico. The NJRU populations are of conservation interest because of unique and potentially adaptive genetic diversity and lower levels of mitochondrial and nuclear genetic diversity than the Northern and Southern populations, but more importantly, peripheral populations (such as NJRU) are of conservation and genetic management concern because they have a greater likelihood of undergoing a local extinction in the short term due to lower effective sizes. Samples were very limited, from the standpoint of the NJRU, from Sinaloa and Jalisco; therefore, the addition of 20 or more samples from Sinaloa and Jalisco would be valuable to further this study. Two of the three samples we obtained from Sinaloa did not yield DNA, and the third sample did not have good-quality DNA for conducting the analyses. 


\section{Introduction}

The jaguar is the largest Neotropical felid and the only extant representative of the genus Panthera in the Americas. Jaguar fossils have been located in North America as far north as Nebraska and Washington (Seymour, 1989; Turner and Anton, 1997). In recorded history, jaguar range has extended from the Southern United States, throughout Mexico, to Central, and South America. As of 2016, jaguars have been extirpated from much of this area and subsequently reside in a much-reduced, and fragmented range (Nowell and Jackson, 1996). They occupy a wide variety of habitats including rainforest, flooded marshes, and open scrubland (Oliveira, 1994), as well as dry tropical forest (Sonora, Mexico), and Madrean forest (Arizona) (Brown and Lopez-Gonzalez, 2001). Effective conservation and management strategies for jaguars require reliable knowledge of the structure and history of jaguar populations; therefore, Eizirik and others (2001) published a phylogeographic and population history for jaguars using genetic methods. Phylogeography uses molecular genetic markers to reconstruct the evolutionary relationship of individuals/populations, and incorporates that relation in the background of current geographical distribution and knowledge of major historical processes that may have shaped the current jaguar distribution. The results of Eizirik and others (2001) showed no complete barriers to gene flow for jaguars, and no major subdivisions such as subspecies. (Gene flow refers to an individual emigrating out of one population, immigrating into another population, and successfully reproducing, thereby incorporating its genes into the new population so that the event is detectable by genetic techniques.) There were some incomplete barriers to gene flow such as the Amazon River and the Darien straits between North and South America (Eizirik and others, 2001). The only result that was supported by all molecular markers used in this study was that of two populations separated by the Amazon River, with the Amazon River significantly limiting gene flow but not being a complete barrier. The authors inferred from their results high historical levels of gene flow among jaguar populations over broad areas. High levels of gene flow generally mean at least 1 migrant per generation, and as many as 10 migrants per generation, for adjacent populations.

The States of Arizona, United States, and Sonora, Mexico, have been part of the historical distribution of jaguars; however, poaching and habitat fragmentation have limited their distribution until they were declared extinct in the United States (Nowell and Jackson, 1996) and endangered in Sonora (Secretaría de Desarrollo Social, 1997). However, in 1996, two wild, free roaming jaguars were photographed and filmed in Arizona and New Mexico ((by Warner Glenn in New Mexico, see Glenn 1996; and by Jack Childs in Arizona, see Childs and Childs, 2008)). David Brown and Carlos Lopez Gonzalez, large cat specialists, set out to determine the origin of these two jaguars. They identified three metapopulations in Sonora, covering $70,000 \mathrm{~km}^{2}$ (Lopez-Gonzalez and Brown, 2002). Currently, this jaguar metapopulation serves as one of the core populations for what the U.S. Fish and Wildlife Service Jaguar recovery team has defined as the Northern Jaguar Recovery Unit (fig. 1).

Because this jaguar population was only recently identified (1996), samples from this population were not included in the rangewide jaguar taxonomy/phylogeography study described earlier in this section, as its existence was not known at the time of that study. Therefore, a need was apparent to have this northernmost (Arizona/Sonora) jaguar population included in overall analyses of jaguar molecular taxonomy and genetic diversity. The analyses were performed once sufficient samples were available, and the results are presented here. 


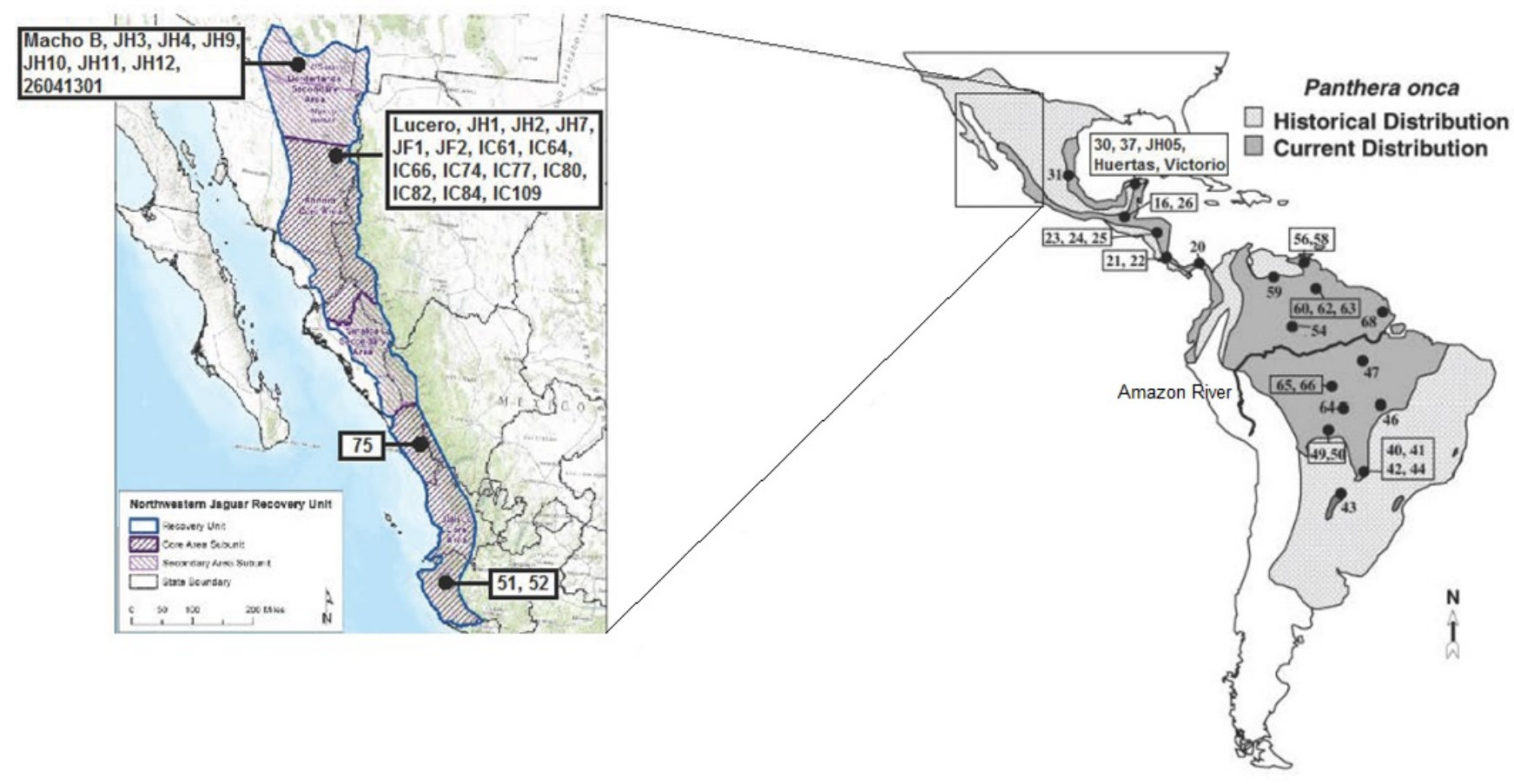

Figure 1. Maps showing historical and current geographical distribution of jaguars [modified from Oliveira (1994) and Eizirik and others (2001)], in North, Central, and South America, and the location of Northern and Southern populations with respect to the Amazon River (right panel); and Northwestern Jaguar Recovery Unit (NJRU) population [modified from Sanderson and Fisher (2013) in North America (left panel). Approximate sample collection sites are represented as black circles. Numbers next to circles are sample identification labels (single numbers after Pon (Panthera onca); table 1) from each area. Only individuals with known regional origin are shown.

This project is part of a binational collaborative effort among many individual biologists and agencies for jaguar conservation and management. Molecular genetic markers were used to examine diversity and taxonomy for jaguars in southern Arizona and the Mexican states of Sonora, Sinaloa, and Jalisco. The goals of this study were to (1) determine the level of genetic diversity at felid microsatellite DNA markers for this northwestern population of jaguars (living in the Northwestern Jaguar Recovery Unit, hereinafter referred to as the NJRU), and (2) compare this diversity to jaguars across their rangethroughout eastern Mexico, and Central and South America. This study also examined these NJRU jaguars from a taxonomic perspective to determine if they are a separate Evolutionarily Significant Unit (ESU) relative to jaguars in other parts of the jaguar range. An ESU can refer to a subspecies or population and implies geographic separation of that taxa/population, as well as evolutionary adaptations that distinguish that subspecies or population from all other populations of the same species (Moritz, 1994). 


\section{Study Objectives}

The objectives of this study were to:

1. Collect opportunistic jaguar samples (hide, blood, hair, saliva, and scat), from historical and current individuals, that originated in NJRU areas of Arizona, New Mexico, and Sonora;

2. Use these samples to assess molecular taxonomy of NJRU jaguars compared to data from a previous study of jaguars rangewide (Eizirik and others, 2001); and

3. Develop suggestions for conservation of NJRU jaguars based on the results.

\section{Materials and Methods}

We include all the sample information in this section, including downloading of the Eizirik and others, (2001) data, and a limited amount of results. The limited amount of results included in the section, "Methods and Materials", incudes data from samples that were eliminated from the study because the samples were genetically identified as species other than jaguar, did not work due to low quality DNA, or were identical to other scat samples.

\section{Study Area}

Analyses were performed on three populations of jaguars: (1) NJRU (Arizona, New Mexico, Sonora, and parts of Sinaloa and Jalisco corresponding to the Northern Jaguar Recovery Unit [see fig. 1]), (2) Northern, and (3) Southern. The Northern population is defined as samples collected north of the Amazon River (with the exception of NJRU) but including as far north as the State of San Luis Potosi along the Gulf Coast of Mexico, and the Southern population is defined as samples collected south of the Amazon River and including as far south as the Chaco region of Paraguay (Eizirik and others, 2001; table 1). We included samples processed in our laboratory along with samples from Ivonne Cassaigne at the National Autonomous University of Mexico (UNAM) $(n=3)$, and Eizirik and others $(2001 ; n=42)$ in this study, all of which are shown in table 1.

Table 1. Jaguar samples analyzed in this study.

[Abbreviations are: Pon, Panthera onca; JH, jaguar hide; Prov., Province; P.N., Parque Nacional; N., north; S., south; I-10, Interstate-10; U.S., United States; Mtns., mountains; NJRU, Northwestern Jaguar Recovery Unit; ARCAS, Guatemala Wildlife Rescue and Conservation Association; Cd., Ciudad; CENAP, Centro de Educacao Profissional; IBAMA, Brazillian Institute of Environment and Renewable Natural Resources; PROFAUNA, non governmental organization in Venezuela dedicated to the conservation of natural resources; Prog., program, J.C., Juan Carlos; UNAM, National Autonomous University of Mexico; T., Ted, UAS, Universidad Autonoma de Sinaloa]

\begin{tabular}{|c|c|c|c|c|}
\hline ID & Tissue Type & Geographic Origin & Population & Institution/Collector \\
\hline Pon $16^{*}$ & Whole blood & Guatemala & Northern & ARCAS \\
\hline Pon $20^{*}$ & Skin & Chepo, Panama Prov., Panama & Northern & Summit Zoo ${ }^{d}$ \\
\hline Pon $22 *$ & Skin & Puerto Limon Prov., Costa Rica & Northern & Simon Bolivar Zoo ${ }^{\mathrm{d}}$ \\
\hline Pon $24 *$ & Whole blood & Nicaragua & Northern & Radio Antenna, Managua \\
\hline Pon $25^{*}$ & Skin & Rio San Juan Department, Nicaragua & Northern & Managua Zoo ${ }^{d}$ \\
\hline Pon $26^{*}$ & Skin & Guatemala & Northern & Aurora Zoo ${ }^{\mathrm{d}}$ \\
\hline
\end{tabular}




\begin{tabular}{|c|c|c|c|c|}
\hline ID & Tissue Type & Geographic Origin & Population & Institution/Collector \\
\hline Pon $28^{*}$ & Skin & Peru (Probably) & Northern & Mendoza Zoo $^{d}$ \\
\hline Pon $29^{*}$ & Skin & Southern South America (Probably) & Southern & Montevideo $Z_{0 o}{ }^{d}$ \\
\hline Pon $30^{*}$ & Whole blood & Yucatan State, Mexico & Northern & Proyecto Balam $^{\mathrm{d}}$ \\
\hline Pon $31 *$ & Skin & San Luis Potosi State, Mexico & Northern & Leon $Z_{0 o}{ }^{d}$ \\
\hline Pon $37^{*}$ & Skin & Yucatan State, Mexico & Northern & Zoologico Centenario $^{d}$ \\
\hline Pon $40^{*} \S, 41^{*}, 42^{*}, 44^{*}$ & Whole blood & Mato Grosso do Sul, SW Brazil & Southern & $\begin{array}{l}\text { Project. Carnivoros, CENAP / } \\
\text { IBAMA }\end{array}$ \\
\hline Pon $43 *$ & Whole blood & P. N. Iguacu, Parana State, S Brazil & Southern & $\begin{array}{l}\text { Project. Carnivoros, CENAP / } \\
\text { IBAMA }\end{array}$ \\
\hline Pon $46^{*}$ & Skin & Goias State, Brazil & Southern & Zoologico de Goiana $^{\mathrm{d}}$ \\
\hline Pon $49 *, 50 * \ddagger$ & Whole blood & Chaco, Paraguay & Southern & Itaipu, Paraguay \\
\hline Pon $51^{*}, 52^{*}$ & Skin & Jalisco State, Mexico & NJRU & Idaho State University \\
\hline Pon $54 * \ddagger$ & Whole blood & Amazonas State, Venezuela & Northern & Las Delicias \\
\hline Pon $56^{*} \S, 58^{*}$ & Whole blood & Falcon State, Venezuela & Northern & Las Delicias \\
\hline Pon $59^{*}$ & Whole blood & Barinas State, Venezuela & Northern & Asociacion Ganaderas \\
\hline Pon $60^{*}$ & Whole blood & Bolivar State, Venezuela & Northern & Merida \\
\hline Pon $61^{*}$ & Whole blood & Lara State, Venezuela & Northern & Barquisimento \\
\hline Pon $62 *+, 63 *$ & Whole blood & Bolivar State, Venezuela & Northern & Valencia Castellito \\
\hline Pon $72 *$ & Whole blood & Brazil, unknown State & Southern & CENAP / IBAMA \\
\hline Pon $73 *$ & Whole blood & Brazil, unknown State & Southern & CENAP / IBAMA \\
\hline Pon $75^{*}$ & Whole blood & Sinaloa State, Mexico & NJRU & Brian Miller \\
\hline JH05 & Whole blood & Yucatan State, Mexico & Northern & UNAM \\
\hline Victorio & Whole blood & Yucatan State, Mexico & Northern & UNAM \\
\hline Huertas & Whole blood & Yucatan State, Mexico & Northern & UNAM \\
\hline Merlina $^{c}$ & Whole blood & Southern South America (Probably) & Southern & Rio Grande Zoo, New Mexico ${ }^{\mathrm{d}}$ \\
\hline Lucero $^{c}$ & Whole blood & Sonora State, Mexico & NJRU & Phoenix Zoo, Arizona ${ }^{\mathrm{d}}$ \\
\hline Macho $B^{c}$ & Saliva & South of I-10, Arizona, US & NJRU & Arizona Game and Fish \\
\hline $\mathrm{JH} 1 \uparrow^{\mathrm{c}}$ & Skin & Sonora State, Mexico & NJRU & Arizona Game and Fish \\
\hline $\mathrm{JH} 2 \oplus^{\mathrm{c}}$ & Skin & Sonora State, Mexico & NJRU & John Klump \\
\hline $\mathrm{JH} 3 \uparrow^{\mathrm{c}}$ & Skin & Arizona, US & NJRU & Clell Lee \\
\hline $\mathrm{JH} 4^{\mathrm{c}}$ & Skin & Dos Cabezas, Arizona, US & NJRU & John Klump \\
\hline
\end{tabular}




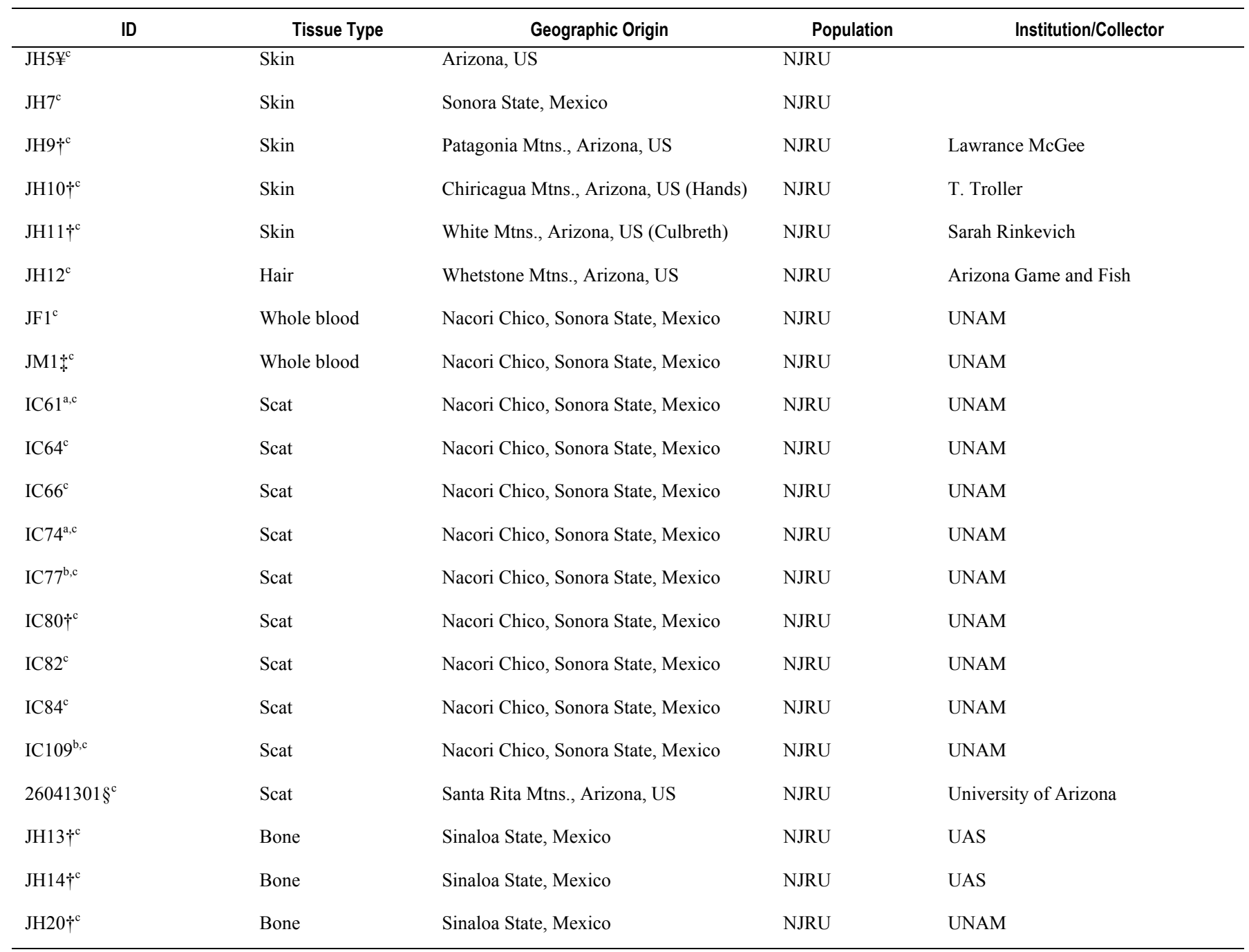

* Samples used originally in Eizirik and others (2001).

$\dagger$ Samples that did not produce high quality genomic DNA and were not included in this study.

$¥$ Ocelot (Leopardus pardalis) sample (not included in this study).

$\$$ Samples typed only for microsatellites (only nuclear genetic information was used for these samples).

$\S$ Samples typed only mtDNA (only mitochondrial genetic information was used for these samples).

${ }^{\text {a }}$ Samples IC61 and IC74 are from the same individual based on mtDNA and microsatellite genetic variation.

${ }^{\mathrm{b}}$ Samples IC77 and IC109 are from the same individual based on mtDNA and microsatellite genetic variation.

${ }^{\mathrm{c}}$ Samples payed for by this contract.

${ }^{\mathrm{d}}$ It is difficult to validate the origin of zoo specimens. However, these samples were selected following discussions between a research team and zoo personnel, and only samples known to be wild born from a particular location were collected. In particular, Lucero was captured on a ranch in Sonora, Mexico, prior to being brought to a zoo.

NJRU = Northwestern Jaguar Recovery Unit; CENAP / IBAMA = Centro Nacional de Pesquisa e Conserva

Irãstidet Mamíferos Brasileiro do Meio Ambiente e dos Recursos Naturais Renováveis; UNAM = Universidad Nacional Autónoma de México; UAS = Universidad Autonoma de Sinaloa. 


\section{DNA Extraction and Species Identification}

We used the DNeasy Blood and Tissue Kit (Qiagen Inc., Valencia, California) to isolate genomic DNA from blood, hide, hair, and saliva samples from 15 jaguar individuals (table 1). Fourteen of these individuals were from Arizona and Sonora (NJRU population), and one was from the Rio Grande Zoo, New Mexico (possibly from the Southern population). The extracted DNA from one Southern individual was used as a positive control. We performed DNA extractions from blood samples from individuals captured in Mexico (JF1, and JF2) at UNAM following local legislation specifications for endangered species. Additionally, we used the Qiamp DNA Stool Kit to extract DNA from epithelial cells (cells from the lining of the digestive tract) from 10 jaguar scat samples from Arizona and Sonora (NJRU population). These scat samples had already been confirmed as jaguar as part of two separate studies; Ivonne Cassaigne (at UNAM) allowed us to use the Sonora scat samples and the Arizona scat sample already at the Culver Laboratory were part of a separate study. We sequenced all 10 scat samples and genotyped the 9 Sonora scat samples as part of this study. The Arizona scat sample was not successfully genotyped at the time of this report.

We confirmed jaguar authenticity for 14 out of the 15 blood, hide, hair, and saliva samples collected using polymerase chain reaction (PCR) for the mitochondrial DNA (mtDNA) cytochrome $b$ cytB gene DNA sequencing at the University of Arizona Genomics Core (UAGC) facility. Only hide sample JH5 was determined to be from an ocelot [Leopardus pardalis] (table 1). In total, there were 24 genetically confirmed jaguar samples.

\section{mtDNA Control Region Amplification and Sequencing}

For positively identified jaguar samples, we examined another (mtDNA) region. The mtDNA molecule contains 37 genes and a non-coding (does not code for a gene) region known as the control region, which shows much genetic variation. We amplified the mtDNA control region using (PCR) and primers L15997 (Lopez and others, 1996) and H16498 (Ward and others, 1991), and PAN-CCR-F and PAN-CCR-R (Kim and others, 2001), following the same conditions as in Eizirik and others (2001). As above, PCR products were sequenced at the UAGC facility. We aligned individual forward and reverse DNA sequences in Sequencher ${ }^{\mathrm{TM}}$.

\section{Microsatellite PCR Amplification and Genotyping}

Microsatellites are repeated sequences with a length of 2-6 nucleotides (or base pairs, which make up the sequence of DNA). The genetic variation is formed by different alleles having different numbers of repeats; thus, the alleles are of differing lengths. For positively identified jaguar samples, we amplified 28 nuclear microsatellite loci (FCA005, FCA008, FCA026, FCA043, FCA075, FCA077, FCA090, FCA091, FCA094, FCA096, FCA097, FCA098, FCA105, FCA126, FCA139, FCA161, FCA193, FCA201, FCA211, FCA220, FCA224, FCA229, FCA247, FCA290, FCA310, FCA441, FCA453, and FCA678; Menotti-Raymond and others, 1999) using the same PCR conditions as in Eizirik and others (2001). We submitted PCR products to the UAGC facility for fragment analysis and used Genotyper ${ }^{\circledR}$ software version 3.7 (Applied Biosystems, Foster City, California) to precisely calculate the sizes of the fragments and to discard ambiguous or low-quality amplified genotypes. 


\section{Final Sample Inclusions for Analyses}

We amplified the mtDNA control region and 28 nuclear microsatellites for positively identified jaguar samples (table 1). However, we eliminated from our study repeated samples defined as samples that had mtDNA control region haplotypes and nuclear microsatellite genotypes identical to samples previously collected. In this regard, scat sample IC61 was identical to scat sample IC74, and scat sample IC77 was identical to scat sample IC109 (which is not unlikely, given that different collected scats could have been deposited by the same individual). We, therefore, eliminated samples IC74 and IC109 from further analyses. We also were unable to amplify the mtDNA control region in two samples (JF2 and IC80) and the complete panel of 28 nuclear microsatellites in two samples (IC80 and 26041301). JF2 and IC80 were removed from downstream mtDNA analysesl IC80 and 26041301 were removed from downstream microsatellite analyses.

\section{mtDNA Statistical Analyses}

We downloaded mtDNA control region sequences from three NJRU jaguars (from Jalisco and Sinaloa, Mexico), 19 Northern jaguars, and 15 Southern jaguars (Eizirik and others 2001; table 1) from GenBank; and generated mtDNA sequences for 3 Northern jaguars obtained from Ivonne Cassaigne (at UNAM). Combining the Ivonne Cassaigne and Eizirik and others (2001) data with our datasets, we had 16 NJRU, 22 Northern, and 16 Southern jaguar mtDNA control region sequences. We calculated haplotype diversity $(h)$ and nucleotide diversity $(\pi)$ within each hypothetical population (NJRU, Northern, and Southern) in DnaSP version 5.10.01 (Rozas and Rozas, 1995). We used Arlequin version 3.5 (Excoffier and Lischer, 2010) to estimate genetic differentiation levels between population pairs $\left(F_{S T}\right)$ after 1,000 permutations.

We further discussed phylogenetic and phylogeographic patterns after building a minimum spanning network with a 95-percent confidence limit in TCS version 1.2.1 (Clement and others, 2000). For this analysis, jaguar mtDNA control sequences were aligned with a lion (Panthera leo) mtDNA control region sequence (Ple 181; Kim and others, 2001) to be used as an outgroup.

\section{Nuclear Statistical Analyses}

We obtained microsatellite genetic data from three NJRU jaguars (from Jalisco and Sinaloa, Mexico), 22 Northern jaguars, and 17 Southern jaguars from Eduardo Eizirik, and generated microsatellite genotypes for 3 Northern jaguars obtained from Ivonne Cassaigne. Combining the data of Ivonne Cassaigne and Eizirik and others (2001) with our datasets, we had 16 NJRU, 25 Northern, and 18 Southern microsatellite genotypes. Because microsatellite genotypes often are variable among different datasets, we used DNA from samples Pon 51 and Pon 75 (originally used in Eizirik and others, 2001, DNA was obtained directly from the Laboratory of Genomic Diversity) to compare the genetic information of both datasets. We found ambiguous and (or) low-quality genotypes in 6 (FCA005, FCA097, FCA098, FCA290, FCA310, and FCA453) of the 28 microsatellite loci used for this study. These 6 loci were eliminated from our study, resulting in 22 microsatellite loci analyzed. Because of low quality DNA from scat samples, we were only able to include a panel of 6 microsatellite loci for scat samples. 
We estimated allelic richness $(\mathrm{A})$ and observed $\left(\mathrm{H}_{\mathrm{O}}\right)$ and expected heterozygosities $\left(\mathrm{H}_{\mathrm{E}}\right)$ per locus and population, and the Probability of Identity (PID) in Fstat version 2.9.3.2 (Goudet, 1995). To avoid sample-size artifacts (Petit and others, 1998; Leberg, 2002), allelic richness estimates were based on the smallest number of individuals typed for any locus after 1,000 permutations.

Inbreeding coefficient $\left(F_{I S}\right)$ levels within populations and genetic differentiation $\left(F_{S T}\right)$ levels among them also were calculated in Fstat after 1,000 permutations. We preferred to use $F_{S T}$ rather than $R_{S T}$ (Slatkin, 1995) because this index has a lower variance and performs better with small numbers of loci and samples (Gaggiotti and others, 1999). We used Micro-checker version 2.2.3 (van Oosterhout and others, 2004) to evaluate the presence of null alleles that also could cause departures from HardyWeinberg expectations. In cases where null alleles were likely, we estimated an unbiased $F_{S T}$ (Weir, 1996) after correcting for null alleles following the Estimate Null Alleles (ENA) method as implemented in FreeNA (Chapuis and Estoup, 2007).

We further investigated population assignment probabilities for each individual in Structure version 2.3.3 (Pritchard and others, 2000), assuming admixture (interbreeding of two previously separate populations), correlated allele frequencies, and three putative populations (NJRU, Northern, and Southern) as initial parameters. The number of possible clusters $(K)$ ranged from 1 to 10 , with 1,000,000 Markov chain Monte Carlo repetitions, 100,000 burn-in iterations, and 10 simulations per $K$. The most likely number of clusters was determined using the modal value of $\Delta K$ as recommended by Evanno and others (2005). For the identified $K$-value, we used CLUMPP version 1.1.2 (Jakobsson and Rosenberg, 2007) to summarize the population assignment probabilities of each individual across all permutations.

\section{Results}

\section{mtDNA Control Region Genetic Diversity and Structure}

Sequences from the complete mtDNA control region dataset (54 jaguar individuals) comprise 27 different haplotypes defined by 39 polymorphic sites. Seven haplotypes were noted in NJRU jaguars, and 11 haplotypes each were noted in Northern and Southern jaguars (table 2). All haplotypes were unique to their respective geographic region, except for two haplotypes shared between NJRU and Northern populations (fig. 2).

Table 2. Mitochondrial genetic diversity estimates for each jaguar population in this study and the overall sample set.

[n, number in sample; No., number; SE, standard error; NJRU, Northwestern Jaguar Recovery Unit]

\begin{tabular}{lcccc}
\hline $\begin{array}{c}\text { Jaguar } \\
\text { population }\end{array}$ & $\boldsymbol{n}$ & $\begin{array}{c}\text { Number of } \\
\text { different } \\
\text { haplotypes }\end{array}$ & $\begin{array}{c}\text { Haplotype } \\
\text { diversity (SE) }\end{array}$ & $\begin{array}{c}\text { Nucleotide } \\
\text { diversity (SE) }\end{array}$ \\
\hline NJRU & 16 & 7 & $0.829(0.082)$ & $0.0051(0.0001)$ \\
Northern & 22 & 11 & $0.861(0.065)$ & $0.0054(0.0011)$ \\
Southern & 16 & 11 & $0.850(0.077)$ & $0.0084(0.0007)$ \\
\hline All & 54 & 27 & $0.933(0.018)$ & $0.0072(0.0006)$ \\
\hline
\end{tabular}




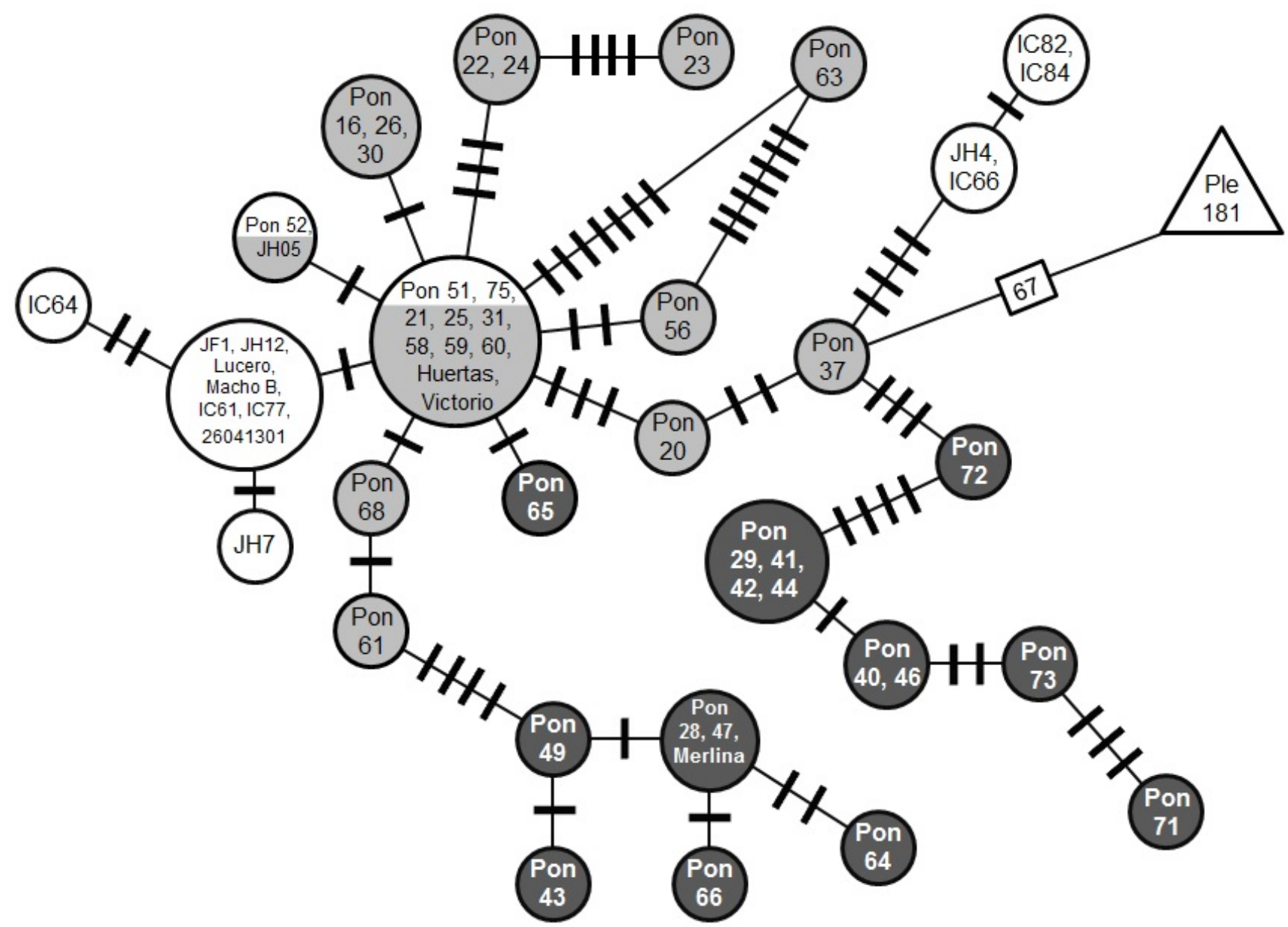

Figure 2. Minimum-spanning network diagram showing phylogenetic and geographical relations among jaguar mitochondrial DNA control region haplotypes (circles) (modified from Eizirik and others, 2001). Area of circle is proportional to haplotype frequency. Labels inside each circle indicate individual jaguars bearing each haplotype. Dark gray circles are haplotypes occurring only in the Southern population. Light gray circles are haplotypes occurring only in the Northern population. White circles are haplotypes occurring only in Northwestern Jaguar Recovery Unit (NJRU) population. Light gray and white circles are haplotypes shared between Northern and NJRU populations. White triangle represents a lion (Panthera leo) haplotype. Bars on connecting lines indicate the exact number of nucleotide differences between haplotypes.

The complete dataset has a haplotype diversity $(h)$ of 0.933 and a nucleotide diversity $(\pi)$ of 0.0072 (table 2). Haplotype and nucleotide diversity estimates among populations range from 0.829 to 0.861 and from 0.0051 to 0.0084 , respectively. The NJRU population consistently shows a lower mtDNA genetic diversity when compared to Northern and Southern populations. 
We found significant levels of mtDNA control region genetic differentiation among all populations $\left(F_{\mathrm{ST}}>0, P<0.05\right.$; table 3 ). The minimum-spanning haplotype network (fig. 2 ) shows that three haplotypes found exclusively in Arizona and Sonora connect to the most common, potentially ancestral, widespread haplotype found in Mexico (Jalisco, Sinaloa, San Luis Potosi, and Yucatan), Costa Rica, Nicaragua, and Venezuela, by 1-3 mutational steps. The other two haplotypes found exclusively in Arizona and Sonora connect to a haplotype found in Yucatan, Mexico (Pon 37), by 4-5 mutational steps; this low divergence among sequences and the part of the network that has a star-like pattern may suggest a series of historical colonization events.

Table 3. Pairwise genetic differentiation $\left(F_{S T}\right)$ values between jaguar populations in this study.

[NJRU, Northwestern Jaguar Recovery Unit; vs., versus; $p$, probability]

\begin{tabular}{lcc}
\hline \multicolumn{1}{c}{ Jaguar population } & Mitochondrial & Nuclear \\
\hline NJRU vs. Northern & $0.218^{*}$ & $0.073^{*}$ \\
NJRU vs. Southern & $0.402^{*}$ & $0.156^{*}$ \\
Northern vs. Southern & $0.289^{*}$ & $0.045^{*}$ \\
\hline
\end{tabular}

$* F_{\mathrm{ST}}>0 ; P<0.05$.

\section{Nuclear Genetic Diversity and Structure}

Overall (59 jaguar individuals), jaguars present a mean allelic richness (A) of 4.990, observed heterozygosity $\left(\mathrm{H}_{\mathrm{O}}\right)$ of 0.573 , and expected heterozygosity $\left(\mathrm{H}_{\mathrm{E}}\right)$ of 0.765 (table 4 ), and PID of 9.8E-31. In the populations examined (NJRU, Northern, and Southern), mean allelic richness ranged from 3.667 to 4.871 , mean observed heterozygosities from 0.434 to 0.653 , and mean expected heterozygosities from 0.614 to 0.764 . The NJRU has lower levels of nuclear genetic diversity than Northern and Southern populations. All populations (including the overall sample set) show significant Hardy-Weinberg deviations $\left(F_{\mathrm{IS}}>0, P<0.05\right)$. The NJRU population, however, has a higher inbreeding coefficient $\left(F_{\text {IS }}\right.$ $=0.292, P<0.05)$ than Northern $\left(F_{\mathrm{IS}}=0.222, P<0.05\right)$ and Southern $\left(F_{\mathrm{IS}}=0.145, P<0.05\right)$ populations.

Only the NJRU population compared to the Southern population has a high and significant nuclear genetic differentiation $\left(F_{\mathrm{ST}}=0.156, P<0.05\right)$. We found no significant nuclear genetic differentiation $\left(F_{\mathrm{ST}}=0.073, P>0.05\right)$ between NJRU and Northern populations (table 3$)$. The Bayesian population structure analysis suggests the presence of two genetic clusters (fig. 3) with no spatial correlation (fig. 4). Overall, it is difficult to assign random individuals to their population of origin (NJRU, Northern, Southern; fig. 4), meaning there is much population mixing (gene flow). 


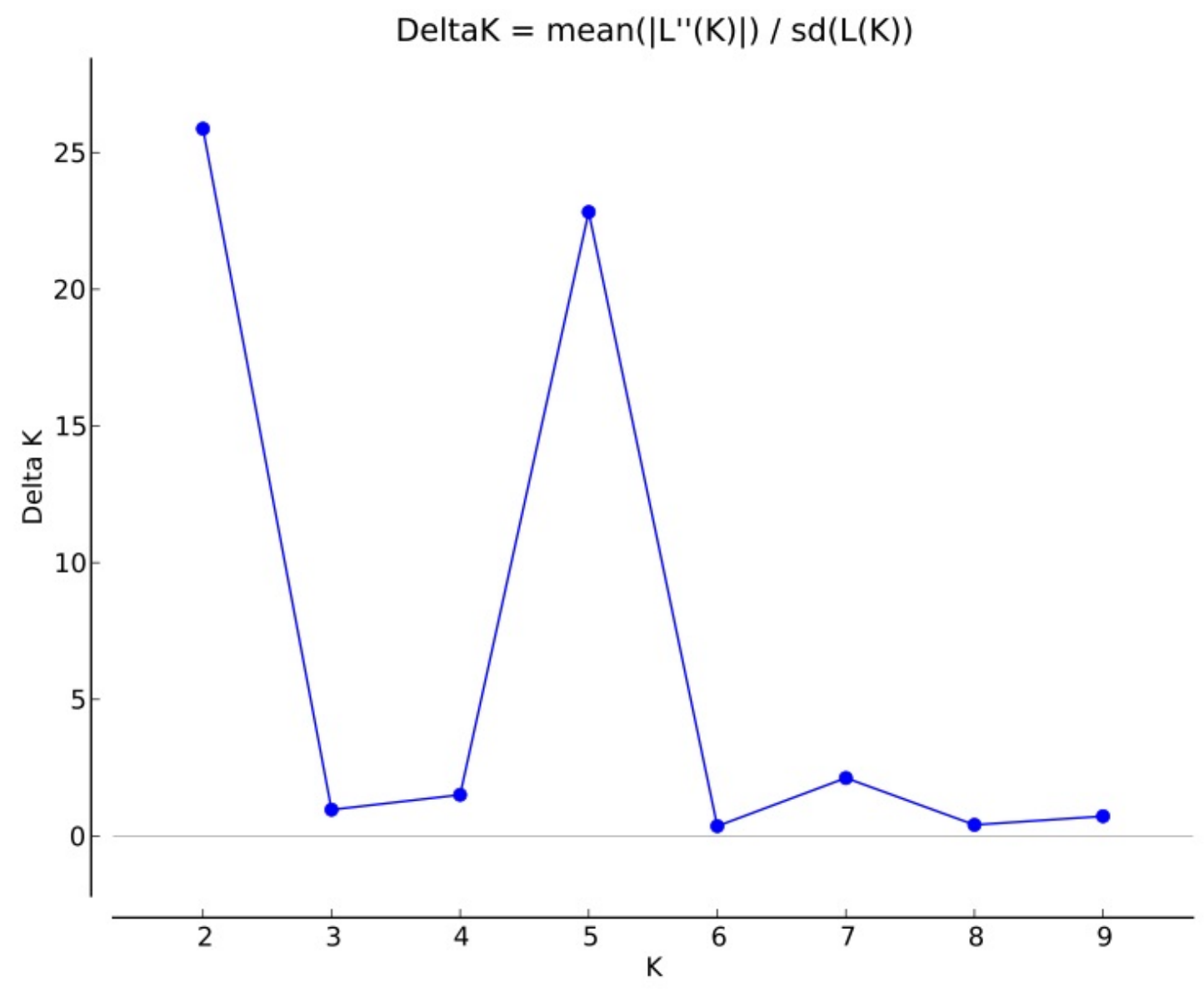

Figure 3. Graph showing number of genetic clusters $(K)$ as function of model value of Delta $K$, as recommended by Evanno and others (2005).

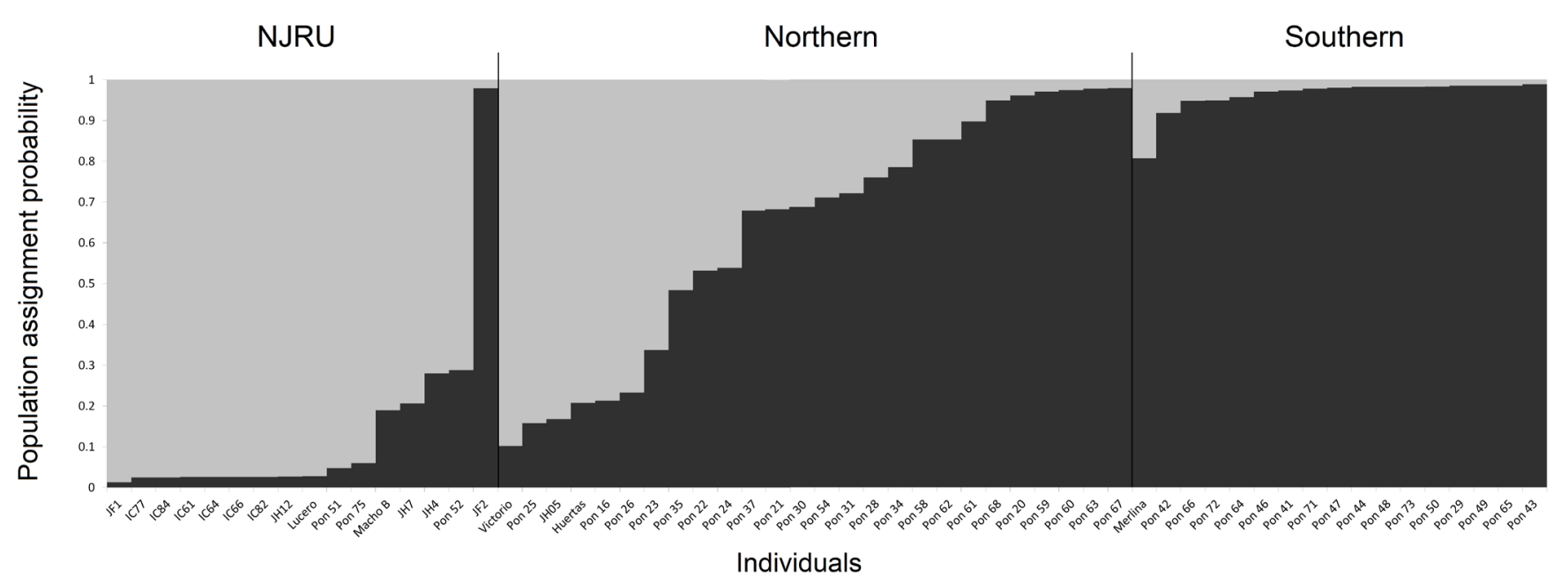

Figure 4. Graph showing population assignment test of jaguars according to their geographic origin (Northwestern Jaguar Recovery Unit [NJRU], Northern, Southern). Genetic population clusters (K=2) are coded with different colors (light gray and dark gray) and were inferred with the program Structure. Individual assignment probabilities to particular clusters also are indicated. 
Table 4. Nuclear genetic diversity $\left(H_{E}\right.$ and $\left.A\right)$ and inbreeding $\left(F_{I S}\right)$ values for each jaguar population and the overall sample set.

[NJRU, Northwestern Jaguar Recovery Unit; $n$, number of samples; A, allelic richness; $\mathrm{H}_{\mathrm{O}}$, observed heterozygosity; $\mathrm{H}_{\mathrm{E}}$ expected heterozygosity; $\mathrm{F}_{I S}$, inbreeding coefficient]

\begin{tabular}{|c|c|c|c|c|c|c|c|c|}
\hline \multirow{2}{*}{ Locus } & \multicolumn{4}{|c|}{ NJRU $(n=16)$} & \multicolumn{4}{|c|}{ Northern $(n=25)$} \\
\hline & A & $\mathrm{Ho}_{\mathrm{o}}$ & $\mathrm{H}_{\mathrm{E}}$ & $F_{I S}$ & A & $\mathrm{Ho}_{\mathrm{o}}$ & $\mathrm{HE}_{\mathrm{E}}$ & $F_{/ S}$ \\
\hline FCA008 & 4.375 & 0.500 & 0.625 & 0.200 & 4.657 & 0.615 & 0.801 & 0.232 \\
\hline FCA026 & 2.111 & 0.111 & 0.222 & 0.500 & 4.671 & 0.500 & 0.738 & $0.323^{*}$ \\
\hline FCA043 & 2.908 & 0.222 & 0.604 & 0.632 & 3.136 & 0.421 & 0.627 & 0.329 \\
\hline FCA075 & 4.327 & 0.667 & 0.785 & 0.150 & 6.316 & 0.810 & 0.886 & 0.086 \\
\hline FCA077 & 4.626 & 0.714 & 0.805 & 0.113 & 4.809 & 0.500 & 0.801 & $0.376^{*}$ \\
\hline FCA090 & 4.089 & 0.875 & 0.652 & -0.343 & 4.461 & 0.889 & 0.750 & -0.185 \\
\hline FCA091 & 2.875 & 0.625 & 0.643 & 0.028 & 3.536 & 0.500 & 0.708 & 0.294 \\
\hline FCA094 & 3.214 & 0.250 & 0.536 & 0.533 & 3.868 & 0.320 & 0.681 & $0.530^{*}$ \\
\hline FCA096 & 3.666 & 0.667 & 0.681 & 0.020 & 5.314 & 0.667 & 0.841 & 0.207 \\
\hline FCA105 & 1.625 & 0.125 & 0.125 & 0.000 & 4.113 & 0.609 & 0.685 & 0.111 \\
\hline FCA126 & 3.787 & 0.133 & 0.702 & $0.810^{*}$ & 4.122 & 0.546 & 0.745 & 0.267 \\
\hline FCA139 & 4.456 & 0.875 & 0.786 & -0.114 & 4.241 & 0.750 & 0.759 & 0.012 \\
\hline FCA161 & 5.441 & 1.000 & 0.824 & -0.213 & 5.338 & 0.667 & 0.824 & 0.191 \\
\hline FCA193 & 4.020 & 0.667 & 0.708 & 0.059 & 6.724 & 0.765 & 0.908 & 0.158 \\
\hline FCA201 & 1.000 & 0.000 & 0.000 & - & 1.775 & 0.091 & 0.174 & 0.478 \\
\hline FCA211 & 2.793 & 0.133 & 0.369 & $0.639 *$ & 5.360 & 0.550 & 0.849 & $0.352 *$ \\
\hline FCA220 & 3.492 & 0.125 & 0.679 & $0.816^{*}$ & 5.294 & 0.667 & 0.814 & 0.181 \\
\hline FCA224 & 2.934 & 0.000 & 0.714 & $1.000 *$ & 5.006 & 0.609 & 0.801 & 0.240 \\
\hline FCA229 & 4.444 & 0.667 & 0.785 & 0.150 & 5.839 & 0.609 & 0.860 & $0.292 *$ \\
\hline FCA247 & 6.000 & 1.000 & 0.875 & -0.143 & 4.159 & 0.588 & 0.726 & 0.190 \\
\hline FCA441 & 4.821 & 0.500 & 0.735 & $0.320 *$ & 5.253 & 0.750 & 0.807 & 0.071 \\
\hline FCA678 & 2.622 & 0.063 & 0.575 & $0.891 *$ & 4.453 & 0.546 & 0.745 & 0.267 \\
\hline Mean & 3.667 & 0.434 & 0.614 & $0.292 *$ & 4.666 & 0.583 & 0.748 & $0.222 *$ \\
\hline SE & 0.258 & 0.073 & 0.049 & 0.059 & 0.229 & 0.037 & 0.031 & 0.031 \\
\hline
\end{tabular}


Table 4. Nuclear genetic diversity $\left(H_{E}\right.$ and $\left.A\right)$ and inbreeding $\left(F_{I S}\right)$ values for each jaguar population and the overall sample set.-Continued

\begin{tabular}{l|c|c|c|c|c|c|c|c}
\hline \multirow{2}{*}{ Locus } & \multicolumn{7}{|c}{ Southern $(\mathbf{n}=\mathbf{1 8})$} & \multicolumn{4}{c}{ All $(\mathbf{n}=\mathbf{5 9})$} \\
\cline { 2 - 8 } & $\mathbf{A}$ & $\mathbf{H}_{\mathbf{O}}$ & $\mathbf{H}_{\mathrm{E}}$ & $\boldsymbol{F}_{\mathbf{I S}}$ & $\mathbf{A}$ & $\mathbf{H}_{\mathbf{O}}$ & $\mathbf{H}_{\mathrm{E}}$ & $\boldsymbol{F}_{\text {IS }}$ \\
\hline FCA008 & 5.781 & 0.688 & 0.848 & 0.189 & 5.556 & 0.622 & 0.842 & $0.261^{*}$ \\
FCA026 & 4.389 & 0.533 & 0.738 & 0.277 & 5.179 & 0.435 & 0.793 & $0.452^{*}$ \\
FCA043 & 3.721 & 0.412 & 0.728 & 0.434 & 3.616 & 0.378 & 0.703 & $0.463^{*}$ \\
FCA075 & 5.289 & 0.688 & 0.846 & 0.187 & 5.815 & 0.739 & 0.862 & 0.143 \\
FCA077 & 4.700 & 0.824 & 0.783 & -0.052 & 5.035 & 0.655 & 0.812 & $0.194^{*}$ \\
FCA090 & 4.424 & 0.867 & 0.779 & -0.113 & 4.677 & 0.875 & 0.786 & -0.117 \\
FCA091 & 2.931 & 0.444 & 0.674 & 0.340 & 3.791 & 0.515 & 0.734 & $0.298^{*}$ \\
FCA094 & 4.666 & 0.563 & 0.779 & 0.278 & 4.288 & 0.388 & 0.723 & $0.464^{*}$ \\
FCA096 & 6.375 & 0.867 & 0.881 & 0.016 & 5.785 & 0.733 & 0.846 & 0.133 \\
FCA105 & 5.412 & 0.765 & 0.825 & 0.074 & 4.406 & 0.583 & 0.685 & $0.149^{*}$ \\
FCA126 & 5.271 & 0.917 & 0.841 & -0.090 & 4.670 & 0.510 & 0.771 & $0.338^{*}$ \\
FCA139 & 5.266 & 0.857 & 0.854 & -0.003 & 5.041 & 0.810 & 0.810 & 0.001 \\
FCA161 & 4.327 & 0.556 & 0.792 & 0.298 & 6.329 & 0.750 & 0.880 & $0.148^{*}$ \\
FCA193 & 6.048 & 0.692 & 0.869 & 0.203 & 6.852 & 0.718 & 0.912 & $0.213^{*}$ \\
FCA201 & 1.762 & 0.056 & 0.163 & 0.660 & 1.618 & 0.061 & 0.137 & 0.553 \\
FCA211 & 5.206 & 0.722 & 0.830 & 0.130 & 5.045 & 0.491 & 0.806 & $0.391^{*}$ \\
FCA220 & 6.226 & 0.667 & 0.905 & 0.264 & 5.462 & 0.543 & 0.829 & $0.346^{*}$ \\
FCA224 & 4.828 & 0.647 & 0.768 & 0.158 & 4.922 & 0.532 & 0.803 & $0.338^{*}$ \\
FCA229 & 5.208 & 0.714 & 0.838 & 0.148 & 5.699 & 0.652 & 0.859 & $0.241^{*}$ \\
FCA247 & 4.732 & 0.667 & 0.758 & 0.120 & 5.057 & 0.677 & 0.777 & 0.130 \\
FCA441 & 5.739 & 0.867 & 0.862 & -0.006 & 5.953 & 0.709 & 0.864 & $0.180^{*}$ \\
FCA678 & 3.718 & 0.438 & 0.594 & 0.263 & 3.894 & 0.370 & 0.688 & $0.462^{*}$ \\
\hline Mean & 4.871 & 0.653 & 0.764 & $0.145 *$ & 4.990 & 0.573 & 0.765 & $0.252^{*}$ \\
SE & 0.232 & 0.043 & 0.033 & 0.039 & 0.235 & 0.039 & 0.033 & 0.048 \\
\hline
\end{tabular}

*Heterozygote deficiency $(\mathrm{P}<0.05)$ following a Bonferroni correction for multiple tests. 


\section{Discussion}

We only included NJRU jaguar samples in the final analysis that contained high-quality DNA and were able to obtain complete mtDNA control region sequences and (or) nuclear genotypes from these samples. Five unique mtDNA control region haplotypes not discovered anywhere else in the jaguar's range were discovered in jaguars from Arizona and Sonora examined in this study. The other two haplotypes discovered in the NJRU population come from Jalisco and Sinaloa, Mexico, and are not unique but are shared with the Northern population. The unique Arizona/Sonora haplotypes are 1-5 mutational steps away from Northern haplotypes, indicating a recent colonization event (in evolutionary time) for jaguars into the northernmost (Arizona/Sonora) reach of their distribution, but long enough ago to acquire mutations (the mtDNA control region acquires mutations at a rate of about one mutation every 70,000 years; Eizirik and others, 2001). The primary exception to geographically exclusive mtDNA haplotypes are the two haplotypes shared between NJRU and Northern populations, which include jaguars from Mexico (Jalisco, Sinaloa, San Luis Potosi, and Yucatan), Costa Rica, Nicaragua, and Venezuela. Finally, our haplotype network suggests at least two historical colonization events from the Northern population into Arizona and Sonora, as haplotypes exclusively found in Arizona and Sonora derive from two different Northern haplotypes.

NJRU jaguars show lower levels of mitochondrial and nuclear genetic diversity when compared with other jaguar populations (Northern and Southern), further supporting the recent colonization (in evolutionary time) of jaguars into Arizona and Sonora. Jaguar populations (NJRU, Northern, and Southern) show lower levels of nuclear than mitochondrial genetic differentiation, which can happen under scenarios of differential dispersal between males and females (Frankam and others, 2007); the mitochondria is maternally inherited and will indicate female dispersal movements. In jaguars, females do not make long-range movements throughout their reproductive life, and males disperse longer distances. Supporting that female jaguars do not make long range movements is the fact that almost all mtDNA control region haplotypes found in the populations examined in this study (NJRU, Northern, and Southern) are exclusive to their corresponding geographical regions, resulting in significant mtDNA genetic differentiation levels.

\section{Conclusions}

Because of the exclusive geographic location of mtDNA haplotypes in the haplotype network and significant genetic differentiation observed for mtDNA, there is no evidence of recent female jaguar dispersal events either into or out of the Arizona/Sonora area. Recent means a minimum of 15 years ago (when the Sinaloa/Jalisco samples were collected; we can not detect anything more recent than that), and a maximum of 350,000 years ago (the oldest mtDNA lineage in Arizona/Sonora is 5 mutations away from the nearest Northern haplotype, at a rate of 70,000 years per mutation). Male jaguar movements, however, balance the lack of female movement as shown by the absence of differentiation observed with microsatellite markers. Our data suggest that male gene flow among populations is sufficient to avoid loss of genetic diversity. We conclude that there is a lack of strong nuclear genetic structure among Northwestern Jaguar Recovery Unit (NJRU), Northern, and Southern jaguar populations, and we also found no evidence to support major subspecies or Evolutionarily Significant Unit (ESU) divisions in jaguars, including the NJRU. 


\section{Management Implications for Jaguars in Arizona/New Mexico and Mexico}

This study encourages international cooperation for promoting connectivity of different jaguar populations within and among NJRU, Northern and Southern. Low levels of mitochondrial and nuclear genetic diversity present in NJRU are typical of a peripheral population with low effective sizes (number of reproductive individuals). This study promotes NJRU jaguar conservation from a genetic diversity point of view; NJRU jaguars harbor a reservoir of unique mitochondrial haplotypes because other populations (Northern and Southern) have a greater reservoir of genetic diversity. More importantly, peripheral populations are of conservation and management concern because they have a greater likelihood of undergoing a local extinction in the short-run due to their small effective size (relative to larger internal populations), and peripheral populations often harbor rare genetic diversity that might be adaptive, such as rare MHC alleles useful is fighting pathogens specific to a geographic area. As of 2016, there is no evidence suggesting the presence of a jaguar breeding population in Arizona; thus, for Arizona, it is important to protect jaguars in Sonora and in all key breeding and connective areas in Mexico. For Arizona and Sonora combined, it is important to maintain connectivity to all other potential jaguar populations in Mexico (Northern population), thus maintaining the pattern of gene flow among populations.

\section{Further Research}

Additional research that could contribute the most to these results would be the addition of more samples to this dataset. We are in the process of obtaining three additional Arizona/Sonora samples from museums, including the Smithsonian Museum, which houses the type specimen from Arizona. The most important samples, however, from the standpoint of the NJRU, come from Sinaloa and Jalisco. As od 2016, we have more than 20 samples from the States of Arizona and Sonora, but 1 sample from Sinaloa, and 2 samples from Jalisco. Those samples clustered with eastern Mexico rather than with Arizona/Sonora, but that could be an artifact of low sample sizes. Therefore, the addition of 20 or more samples from Sinaloa and Jalisco would be valuable. Two of the three samples we obtained from Sinaloa did not yield DNA, and the third did not have sufficiently good-quality DNA to use in our analyses. 


\section{Acknowledgments}

The authors would like to thank the following individuals/agencies for their assistance with this project:

- Carlos Lopez Gonzalez (Universidad Autonoma de Queretero) and Dave Brown (Arizona State University) for the collection of all but one (JH11) Arizona/Sonora hide sample used in this study;

- Sarah Rinkevich U.S. Fish and Wildlife Serivce) for collecting the JH11 hide sample;

- The Arizona Game and Fish Department and Anne Justice-Allen for allowing us to use a blood sample from Macho B and hair sample from JH12, and for facilitating our collection of blood from the Lucero captive jaguar;

- The Rio Grande Zoo for sending a blood sample from the Merlina captive jaguar;

- Ivonne Cassaigne and Rodrigo Medellin (UNAM) for allowing us to use blood from jaguars in their study sites in the Yucatan and Sonora, Mexico;

- Eduardo Eizirik (PUCRS) for providing all his raw data to allow comparisons to his previous jaguar data; and

- The National Cancer Institute for providing access to jaguar blood and DNA samples from South American jaguars allowing calibration of our data set to the Eizirik data set.

\section{References Cited}

Brown, D.E., and Lopez-Gonzalez, C.A., 2001, Borderland jaguar: Salt Lake City, University of Utah Press, $170 \mathrm{p}$.

Chapuis, M.P., and Estoup, A., 2007, Microsatellite null alleles and estimation of population differentiation: Molecular Biology and Evolution, v. 24, p. 621-631.

Childs, J.L., and Childs, A.M., 2008, Ambushed on the Jaguar Trail: Hidden Cameras on the Mexican Border, Rio Nuevo Publishers, $151 \mathrm{p}$.

Clement, M., Posada, D., and Crandall, K., 2000, TCS-A computer program to estimate gene genealogies: Molecular Ecology, v. 9, p. 1,657-1,660.

Eizirik, E., Kim, J.-H., Menotti-Raymond, M., Crawshaw, P.G., O’Brien, S.J., and Johnson, W.E., 2001, Phylogeography, population history and conservation genetics of jaguars (Panthera onca, Mammalia, Felidae): Molecular Ecology, v. 10, p. 65-79.

Evanno, G., Regnaut, S., and Goudet, J., 2005, Detecting the number of clusters of individuals using the software STRUCTURE_A simulation study: Molecular Ecology, v 14, p. 2,611-2,620.

Excoffier, L., and Lischer, H.E.L., 2010, Arlequin suite version 3.5-A new series of programs to perform population genetics analyses under Linux and Windows: Molecular Ecology Resources, v. 10, p. 564-567.

Frankham, R., Ballou, J.D., and Briscoe, D.A., 2007, Introduction to conservation genetics: Cambridge, United Kingdom, Cambridge University Press, 618 p.

Gaggiotti, O.E., Lange, O., Rassmann, K., and Gliddons C., 1999, A comparison of two indirect methods for estimating average levels of gene flow using microsatellite data: Molecular Ecology, v. 8, p. 1,513-1,520. 
Glenn, W., 1996, Eyes of fire: Encounter with a borderlands jaguar: Treasure Chest Publications, 28 p.

Goudet, J., 1995, Fstat version 1.2-A computer program to calculate F-statistics: Journal of Heredity, v. 86 , p. 485-486.

Jakobsson, M., and Rosenberg, N.A., 2007, CLUMPP-A cluster matching and permutation program for dealing with label switching and multimodality in analysis of population structure: Bioinformatics, v. 23, p. 1,801-1,806.

Kim, J.-H., Eizirik, E., O’Brien, S.J., and Johnson, W.E., 2001, Structure and patterns of sequence variation in the mitochondrial DNA control region of the great cats: Mitochondrion, v. 14, p. 279292.

Leberg, P.L., 2002, Estimating allelic richness_-Effects of sample size and bottlenecks: Molecular Ecology, v. 11, p. 2,445-2,449.

Lopez, J.V., Cevario, S., and O'Brien, S.J., 1996, Complete nucleotide sequences of the domestic cat (Felis catus) mitochondrial genome and a transposed mtDNA tandem repeat (Numt) in the nuclear genome: Genomics, v. 33, p. 229-246.

Lopez-Gonzalez, C.A. and Brown, D.E., 2002, Distribución y estado de conservación del jaguar en el noroeste de México, in Medellin, R.A., Chetkiewicz, C., Rabinowitz, A., Redford, K.H., Robinson, J.G., Sanderson, E., and Taber, A., compilers, El jaguar en el nuevo milenio: Fondo de Cultura Economica, Universidad Nacional Autonoma de Mexico, and Wildlife Conservation Society, p. 379 392.

Menotti-Raymond, M., David, V.A., Lyons, L.A., Schäffer, A.A., Tomlin, J.F., Hutton, M.K., and O'Brien, S.J., 1999, A genetic linkage map of microsatellites in the domestic cat (Felis catus): Genomics, v. 57, p. 9-23.

Moritz, C., 1994, Defining 'Evolutionarily Significant Units' for conservation: Trends in Ecology and Evolution, v. 9, no. 10, p. 373-375.

Nowell, K., and Jackson, P., 1996, Wild cats-Status, survey and conservation action plan: IUCN/SSC Cat Specialist Group, 382 p.

Oliveira, T.G., 1994, Neotropical cats-Ecology and conservation: Sao Luis, Brazil, Editora da Universidad Federal do Maranhao (EDUFMA).

Petit, R.J., El Mousadik, A., and Pons, O., 1998, Identifying populations for conservation on the basis of genetic markers: Conservation Biology, v. 12, p. 844-855.

Pritchard, J.K., Stephens, M., and Donelly, P., 2000, Inference of population structure using multilocus genotype data: Genetics, v. 155, p. 945-959.

Rozas, J., and Rozas, R., 1995, DnaSP, DNA sequence polymorphism-An interactive program for estimating population genetics parameters from DNA sequence data: Computer Applications in the Biosciences, v. 11, p. 621-625.

Sanderson, E.W., and Fisher, K., 2013, Jaguar habitat modeling and database update: U.S. Fish and Wildlife Service and Wildlife Conservation Society, $42 \mathrm{p}$.

Secretaría de Desarrollo Social, 1994, NORMA Oficiales Mexicanas (NOM-059-ECOL) que determina las especies de flora y fauna silvestres terrestres y acuáticas en peligro de extinción, amenazadas, raras, y las sujetas a protección especial, que establece especificaciones para su protección. 100 p. Seymour, K.L., 1989, Panthera onca: Mammalian Species, v. 340, p. 1-9. 
Slatkin, M., 1995, A measure of population subdivision based on microsatellite allele frequencies: Genetics, v. 139, p. 457-462.

Turner, A., and Antón, M., 1997, The big cats and their fossil relatives: New York, Columbia University Press, $234 \mathrm{p}$.

van Oosterhout, C., Hutchinson, W.F., Wills, D.P.M., and Shipley P., 2004, MICRO-CHECKERSoftware for identifying and correcting genotyping errors in microsatellite data: Molecular Ecology Notes, v. 4, p. 535-538.

Ward, R.H., Frazier, B.L., Dew-Jager, K., and Pääbo, S., 1991, Extensive mitochondrial diversity within a single Amerindian tribe: Proceeedings of the National Academy of Sciences, v. 88, p. 8,720-8,724.

Weir, B.S., 1996, Genetic data analysis II: Sunderland, Massachusetts, Sinauer Associates, Inc.

Wright, S., 1931, Evolution in Mendelian populations: Genetics, v. 16, p. 97-259.

Wright, S., 1932, The roles of mutation, inbreeding, crossbreeding, and selection in evolution: Proceedings of the Sixth International Congress of Genetics, v. 1, p. 356-366. 
Publishing support provided by the U.S. Geological Survey Science Publishing Network, Menlo and Tacoma Publishing Service Centers

For more information concerning the research in this report, contact the Leader, Arizona Cooperative Fish and Wildlife Research Unit U.S. Geological Survey 325 Biosciences East Tucson, Arizona 85721 http://www.coopunits.org/Arizona/ 


\section{㞭}

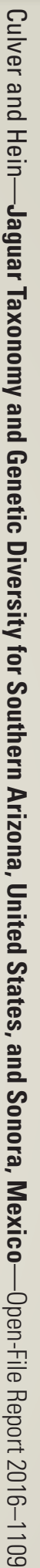

